\title{
Kinerja Mesin Ekstraksi Pati Sagu Tipe Vertikal Stirrer Rotary Blade Menggunakan Saringan 100 mesh pada Berbagai Durasi Waktu Ekstraksi
}

\section{Performance of Vertical Stirrer Rotary BladeType of Sago Starch Extraction Machine Using 100 Mesh Screen at Various Extracting Time Duration}

\author{
Darma $^{1 *}$, Desi N. Edowai ${ }^{1}$, Cornelia Boiratan ${ }^{2}$ \\ ${ }^{1}$ Jurusan Teknik Pertanian dan Biosistem, Fakultas Teknologi Pertanian Unipa \\ Jl. Gunung Salju amban, Manokwari 98314. \\ ${ }^{2} J u r u s a n$ Teknologi Hasil Pertanian, Fakultas Teknologi Pertanian Unipa \\ Jl. Gunung Salju amban, Manokwari 98314. \\ "Email: darmabond@gmail.com
}

\begin{abstract}
The objective of this study was to test the performance of a vertical stirrer rotary blade sago starch extraction machine with a 100 mesh screener at several extracting time duration. In the experiment, four levels of extracting time duration i.e. 10, 15, 20, and 25 minutes were examined. The machine performance test was carried out by measuring extraction capacity, starch rendement, starch yield, and starch left in sago pith waste. Results showed that starch rendement and starch yields were increased as time duration increased. Meanwhile, extraction capacity and starch left in waste decreased with time duration increased. Based on the highest starch yield as well as the lowest starch left in waste, the highest performance was obtained at the condition of the extraction time duration of 25 minutes. The machine's performance at the condition were (1) starch rendement $46.87 \%$, (2) starch yield $71 \mathrm{~kg} / \mathrm{hour}(3)$ extraction capacity $150 \mathrm{~kg} / \mathrm{hour}$, and (4) starch left in waste $1.43 \%$.
\end{abstract}

Keywords: extraction machine, sago starch, stirrer rotary blade, starch yield, starch rendement

\begin{abstract}
Abstrak
Tujuan penelitian ini adalah menguji kinerja mesin ekstraksi pati sagu tipe vertical stirrer rotary blade menggunakan saringan 100 mesh pada berbagai durasi waktu ekstraksi. Pengujian kinerja mesin dilakukan pada empat level durasi waktu ekstraksi yaitu 10, 15, 20 dan 25 menit. Evaluasi kinerja dilakukan dengan mengukur parameter (1) rendemen pati, (2) hasil pati, (3) kapasitas ekstraksi dan (4) kehilangan pati pada ampas. Hasil uji kinerja menunjukkan bahwa semakin tinggi durasi waktu ekstraksi, semakin tinggi rendemen pati dan hasil pati, namun kapasitas ekstraksi, dan persentase pati pada ampas semakin rendah. Berdasarkan parameter hasil pati tertinggi dan persentase kehilangan pati pada ampas terendah maka kinerja tertinggi diperoleh pada perlakuan durasi waktu ekstraksi 25 menit. Kinerja mesin pada perlakuan tersebut adalah (1) rendemen pati 46,87\%, (2) hasil pati $71 \mathrm{~kg} / \mathrm{jam}$, (3) kapasitas ekstraksi $150 \mathrm{~kg}$ ela/jam, dan (4) kehilangan pati pada ampas 1,43\%
\end{abstract}

Kata kunci: mesin ekstraksi, pati sagu, tipe stirrer rotary blade, hasil pati, rendemen pati

\section{PENDAHULUAN}

Potensi sagu (Metroxylon sagu Rottb.) di Papua dan Papua Barat sangat besar.Dari 5,5 juta ha potensi sagu nasional, sekitar 96,5\% atau 5,26 juta ha terdapat di Papua dan Papua Barat (Djoefrie et al.,2014; UP4B, 2014). Menurut Bintoro et al., (2018), potensi produksi pati sagu di Kabupaten Mimika,
Papua14-26 ton/ha/tahun. Menurut Jong dan Hoo (2011) potensi produksi hutan sagu alam di Kabupaten Sorong Selatan, Papua Barat 10 15 ton pati kering/ha/tahun, sedangkan menurut Haryanto et al., (2015) potensi produksi pati sagu di Sorong Selatan 9,7 ton/ha/tahun. Dewi et al. (2016) memperkirakan potensi produksi pati sagu di Kabupaten Sorong Selatan sebesar 38 
ton/ha/tahun. Dengan demikian potensi produksi pati sagu di Papua dan Papua Barat rata-rata 74 juta ton/tahun. Potensi sagu yang sangat besar tersebut belum dikelola dan dimanfaatkan secara maksimal. Berdirinya 2 pabrik pengolahan sagu modern di Kabupaten Sorong Selatan, Papua Barat baru memanfaatkan $3,79 \%$ dari total potensi yang ada. Rendahnya pengelolaan dan pemanfaatan sagu ini terutama disebabkan karena sebagian besar pengolahan sagu yang dilakukan masyarakat khususnya di Papua masih bercorak subsisten menggunakan peralatan tradisional.

Pada pengolahan sagu secara tradisional, tahapan yang membutuhkan curahan waktu dan tenaga paling besar dalam adalah penghancuran empulur batang (pith) disusul proses ekstraksi. Sebagian besar curahan waktu yaitu $92,14 \%$ dari total waktu pengolahan tercurah untuk ke dua proses ini (Darma, 2011). Kapasitas penghancuran empulur (penokokan) dan ekstraksi pati (ramas sagu) berturut-turut $19,50 \mathrm{~kg}$ empulur/jam dan 40,25 kg ela/jam (Darma et al., 2020).

Untuk meningkatkan pemanfaatan sumberdaya sagu dan sekaligus pemberdayaan masyarakat pemilik hak ulayat sagu, perlu mendesain mesin pengolahan sagu yang mudah diadopsi dan sesuai dengan kondisi sosio-cultural masyarakat lokal. Untuk maksud tersebut, setiap daerah harus mengembangkan alat dan mesin pertanian yang sesuai dengan kondisi setempat karena pengalaman menunjukkan bahwa introduksi alat dari luar banyak menemui berbagai kendala.

Pada penelitian-penelitian terdahulu (Darma et al., 2010; 2014; 2017), telah dihasilkan prototype mesin ekstraksi pati sagu tipe vertical stirrer rotary blade. Prinsip kerja dari mesin-mesin tersebut semuanya sama yaitu mengkombinasikan pengadukan, peremasan dan penyaringan dalam suatu tabung ekatraksi. Ketiga proses berlangsung secara simultan dalam satu ruang/tabung ekstraksi sehingga konstruksi alat lebih sederhana dibandingkan dengan mesin ekstraksi pati lainnya. Mesin ekstraksi pati sagu tersebut telah digunakan oleh masyarakat di beberapa lokasi di Provinsi Papua dan Papua Barat.

Salah satu faktor penting yang mempengaruhi kinerja mesin ekstraksi pati adalah ukuran lubang komponen saringan (screen apertures size). Darma et al., (2010; 2014; 2017) menggunakan saringan dengan ukuran lubang berdiameter berturut-turut 1,5 $\mathrm{mm}, 1 \mathrm{~mm}$ dan $0,25 \mathrm{~mm}$ (60 mesh). Solissa (2019) menggunakan saringan dengan ukuran lubang $0,5 \mathrm{~mm}$. Penggunaan saringan dengan ukuran lubang tersebut di atas, memerlukan penyaringan tahap ke-2 karena tidak hanya pati yang lolos tapi juga ampas berukuran kecil/halus. Penggunaan saringan tahap ke-2 ini mengurangi efisiensi mesin karena harus dikontrol secara terus-menerus selama proses ekstraksi berlangsung. Untuk mengatasi masalah tersebut perlu menggunakan saringan dengan diameter lubang yang lebih kecil sehingga tidak diperlukan lagi saringan tahap ke-2.

Tujuan penelitian ini adalah menguji kinerja saringan 100 mesh pada berbagai waktu ekstraksi dari mesin ekstraksi pati sagu tipe vertical stirrer rotary blade. Dari hasil penelitian ini akan diketahui kinerja mesin dengan menggunakan saringan 100 mesh sehingga dapat dijadikan dasar dalam pengembangan dan penerapan prototype selanjutnya untuk meningkatkan efektivitas dan effisiensi mesin.

\section{METODOLOGI}

\section{Konstruksi dan prinsip kerja mesin ekstraksi pati sagu tipe vertical stirrer rotary blade}

Secara keseluruhan, konstruksi mesin ekstraksi pati sagu ini sama dengan prototipe terdahulu (Darma et al., 2014 dan 2017), perbedaannya hanya pada ukuran lubang saringan yang digunakan. Di samping itu, ditambahkan juga bilah horizontal yang dimaksudkan untuk meningkatkan efektivitas ekstraksi. Pada Gambar 1 ditampilkan konstruksi mesin ekstraksi pati sagu tipevertical stirrer rotary blade yang diuji pada penelitian ini. 

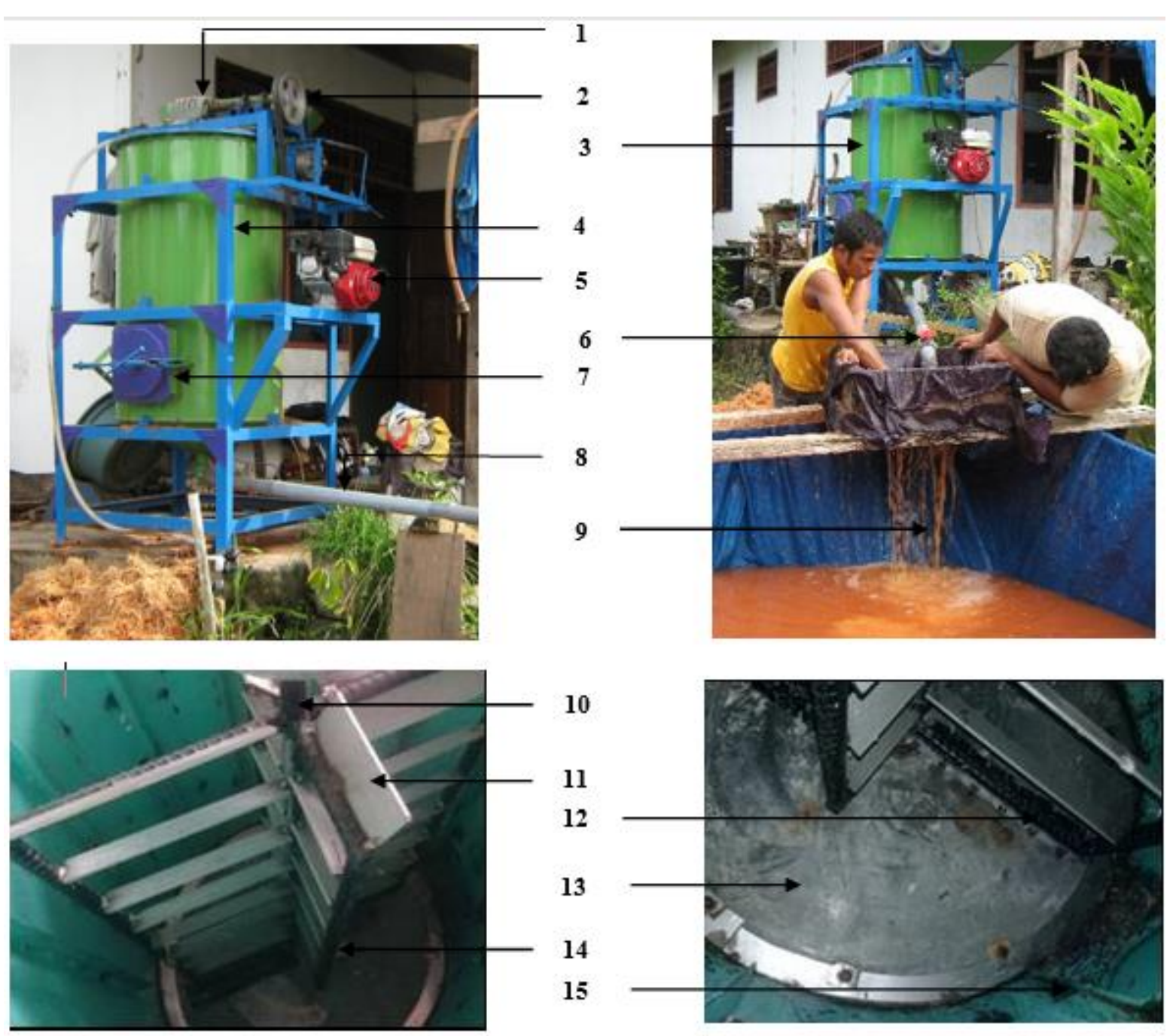

(1) reduction gear box, (2) pulley gear box, (3) tabung ekstraksi , (4) rangka utama, (5) motor penggerak, (6) stop cran (7) pintu pengeluaran ampas, (8) pipa penyalur suspense pati, (9) bak pengendapan pati, (10) poros pengaduk, (11) bilah horizontal, (12) pembersih saringan, (13) saringan 100 mesh, (14) bilah vertical, (15) bilah stasioner

Gambar 1. Konstruksi mesin ekstraksi pati sagu tipe vertical stirrer rotary blades

Mesin pengekstrak pati sagu ini sebagaimana terlihat pada Gambar 1 terdiri dari beberapa bagian utama yaitu: rangka utama (4), tabung ekstraksi (3) komponen transmisi daya berupa reductiongear box wpx80, pulley, dan v-belt $(1,2)$,motor penggerak menggunakan honda GX 200, 6,5 hp (5), pipa penyalur patiberupa pipa PVC 2 inch yang dilengkapi dengan stop kran pada ujung keluaran mengontrol aliran suspensi pati yang keluar dari tabung ekstraksi $(6,8)$, komponen pengaduk yang terdiri dari poros, bilah horizontal dan bilah vertical $(10,11$, 14).Pada dasar tabung terdapat saringan 100 mesh (13). Bagian bawah tabung dibuat berbentuk kerucut agar tidak terjadi endapan pati di dasar tabung. Untuk meningkatkan efektifitas proses ekstraksi, bagian ujung pengaduk dilengkapi dengan pembersih saringan yang berfungsi untuk mencegah tersumbatnya lubang-lubang saringan oleh butiran pati. Bagian permukaan tabung bagian dalam dipasangi bilah stasioner (15) yang berfungsi untuk membelokkan aliran bubur pati (slurry) pada saat extraksi sehingga tercipta aliran turbulensi. Untuk menampung pati hasil ekstraksi dibuat bak penampung berbentuk kotak yang dilapisi terpal kedap air.

Prinsip kerja dari mesin ekstraksi pati ini sama dengan alat ekstraksi pati sagu manual 
yaitu mengkombinasikan proses peremasan, pengadukan dan penyaringan sehingga pati terpisah dari ampas.Proses peremasan, pengadukan dan penyaringan berlansung secara simultan dalam suatu ruang ekstraksi sehingga konstruksi alat lebih sederhana dibandingkan dengan mesin ekstraksi tipe lainnya.

Sebelum dilakukan proses ekstraksi, terlebih dahulu empulur batang sagu dihancurkan menggunakan mesin parut sagu tipe silinder variant-02 (Darma et al., 2020). Proses ekstraksi pati diawali dengan memasukkan air ke dalam tabung ekstraksi sampai $1 / 3$ bagian kemudian ela sebanyak 100 $\mathrm{kg}$ per proses juga dimasukkan ke dalam tabung.Selama proses ekstraksi berlangsung,butiran pati tersuspensi ke dalam air dan selanjutnya dipisahkan dari ampas menggunakan saringan lalu dialirkan ke bak pengendapan melalui pipa penyalur.

\section{Prosedur Uji Kerja}

Pengujian kinerja mesin dilakukan pada 4perlakuan durasi waktu proses ekstraksi yaitu 10, 15, 20 dan 25 menit. Masing-masing perlakuan dilakukan pengujian 3 kali. Evaluasi kinerja dilakukan dengan mengukur parameter: (1) kapasitas ekstraksi, (2) rendemen pati, (3) hasil pati, dan (4) persentase kehilangan pati pada ampas (losses). Data hasil pengukuran dianalisis secara tabulasi dan disajikan dalam bentuk grafik.

Tahapan prosedur uji kinerja ditampilkan pada Gambar 2 dan prosedur pengukuran untuksetiapparameter pengamatan adalah sebagai berikut:

\section{Kapasitas ekstraksi}

Kapasitas ekstraksi adalah kemampuan mesin ekstraksi untuk mengekstraksi pati per satuan waktu, diperoleh dengan menggunakan persamaan (1). Mesin ekstraksi yang tipe stirrer rotary blade menggunakan sistem batch dalam proses ekstraksi. Pada setiap unit percobaan digunakan hancuran empulur sagu (ela/repos) sebanyak $100 \mathrm{~kg}$ dan waktu ekstraksi merupakan waktu total yaitu kumulatif mulai dari memasukkan ela ke dalam tabung, proses ekstraksi dan pengeluaran ampas dari dalam tabung.

$$
K E=\frac{m_{E}}{t}
$$

$K E$ : kapasitas ekstraksi(kg ela/jam)

$m_{E}$ : massa empulur hasil parutan/repos $(\mathrm{kg})$

$t$ : waktu ekstraksi (jam)

\section{Rendemen pati}

Rendemen pati adalah rasio massa pati hasil ekstraksi dengan massa empulur hasil parutan yang diproses, diperoleh menggunakan persamaan 2:

$$
\begin{aligned}
& R P=\frac{m_{P}}{m_{E}} x 100 \% \ldots \ldots \ldots \ldots \ldots \ldots . . . .(2) \\
& R P \text { :rendemen pati }(\%) \\
& m_{P}: \text { massa pati }(\mathrm{kg}) \\
& m_{E}: \text { massa empulur hasil parutana }(\mathrm{kg})
\end{aligned}
$$

\section{Hasil patibasah (freshstarch yield)}

Hasil pati basah adalah massa pati yang diperoleh dari proses ekstraksi per satuan waktu (jam), ditimbang secara langsung dan/atau dengan menggunakan persamaan 3 :

$H P=K E x R P$

$H P$ : hasil pati basah/segar (kg pati/jam)

$K E$ : kapasitas ekstraksi (kg empulur/jam)

$R P$ : rendemen pati (\%)

\section{Kehilangan pati pada ampas}

Untuk menentukanpersentase pati pada ampas, sebanyak $1 \mathrm{~kg}$ sampel ampas sagu diekstraksi ulang secara manual sampai air perasannya jernih. Pati yang dihasilkan ditimbang massanya dan kehilangan pati akibat terikut pada ampas diperoleh menggunakan persamaan 4:

$$
P A=\frac{m_{P A}}{m_{S A}} \times 100 \%
$$

$P A$ : pati pada ampas (\%)

$\mathrm{m}_{P A}:$ massa pati pada ampas $(\mathrm{kg})$

$m_{S A}:$ massa ampas $(\mathrm{kg})$ 


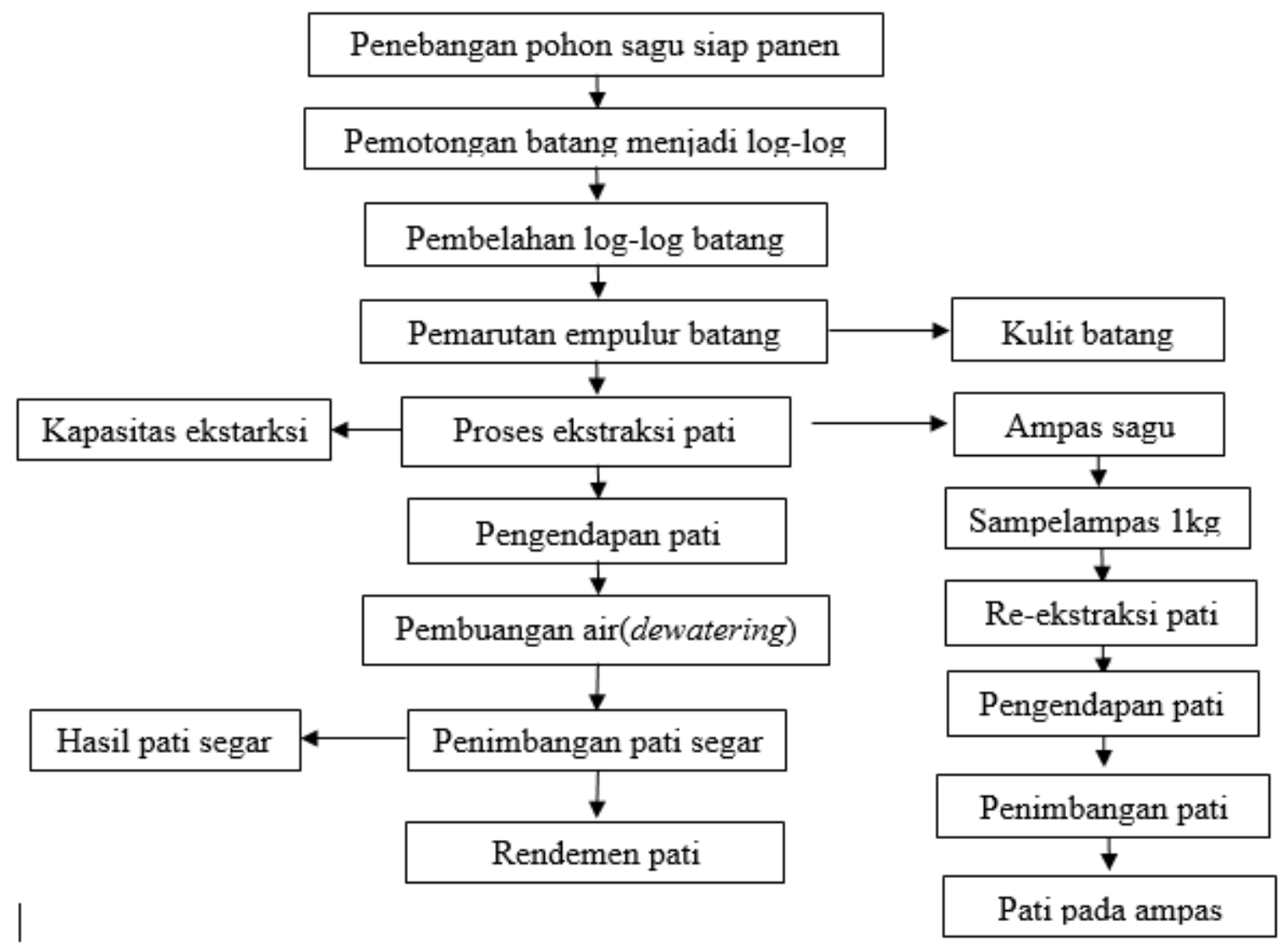

Gambar 2. Bagan alir prosedur uji kinerja mesin ekstraksi tipe vertical stirrer rotary blade

\section{HASIL DAN PEMBAHASAN}

\section{Kapasitas ekstraksi}

Mesin ekstraksi tipe vertikal stirrer rotary blade menggunakan sistem batch dalam pengoperasiannya. Waktu yang diperlukan untuk sekali batch/proses terdiri dari (1) input bahan ke dalam tabung ekstraksi, (2) proses ekstraksi, melibatkan proses pengadukan (stirring), peremasan (squeshing) dan penyaringan (screening), dan (3) pengeluaran ampas sagu dari dalam tabung.

Pada Gambar 3 disajikan kapasitas ekstraksi pada berbagai perlakuan durasi waktu ekstraksi. Berdasarkan Gambar 3 menunjukkan bahwa kapasitas ekstraksi berbanding terbalik dengan durasi waktu ekstraksi. Semakin lama waktu proses ekstraksi maka semakin kecil kapasitas ekstraksi. Hal ini disebabkan karena sebagaimana terlihat pada persamaan (1), kapasitas ekstraksi $(K E)$ berbanding terbalik dengan durasi waktu ekstraksi (t). Kapasitas ekstraksi tertinggi (200 kg ela/jam) diperoleh pada durasi waktu ekstraksi 10 menit dan terendah $(150 \mathrm{~kg}$ ela/jam $)$ diperoleh pada durasi waktu ekstraksi 25 menit.

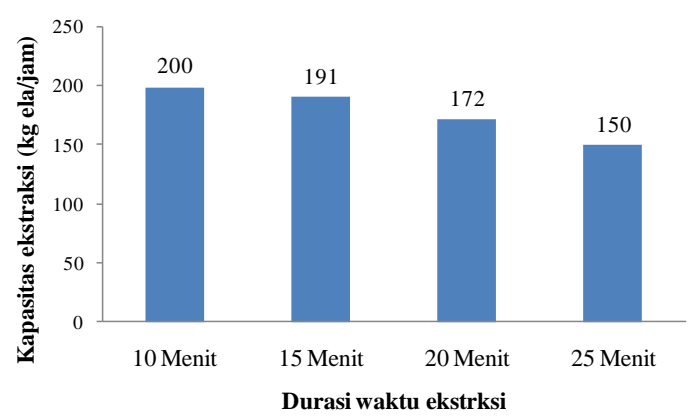

Gambar 3. Kapasitas ekstraksi rata-rata pada berbagai durasi waktu

Kapasitas ekstraksi tersebut sejalan dengan kapasitas ekstraksi prototype sebelumnya yaitu antara $171 \quad-222 \mathrm{~kg} / \mathrm{jam}$ (Darma et al., 2017) dan $204 \mathrm{~kg} / \mathrm{jam}$ (Darma et al., 2014). Namun kapasitas ekstraksi pada penelitian ini lebih rendah dibandingkan dengan hasil penelitian Solissa (2019), dan Darma et al., (2020) yang menghasilkan kapasitas ekstraksi berturut-turut antara 161 - 
$252 \mathrm{~kg} / \mathrm{jam}$ dan $244 \mathrm{~kg} / \mathrm{jam}$. Hal ini disebabkan karena waktu yang diperlukan untuk pengeluaran ampas lebih lama sebagai akibat dari lebih banyak ampas yang tertahan dalam tabung ekstraksi. Pada prototype terdahulu, sebagian ampas halus ikut bersama pati untuk kemudian dipisahkan menggunakan saringan tahap-2 sehingga lebih sedikit ampas yang tertahan dalam tabung, namun dibutuhkan tambahan personil untuk menangani saringan tahap-2 tersebut. Kelebihan mesin dengan menggunakan saringan100 mesh ini adalah tidak diperlukan adanya saringan tahap- 2 .

Total waktu untuk sekali proses adalah kumulatif dari waktu menginput ela ke dalam tabung ekstraksi, proses ekstraksi (pengadukan, peremasan, penyaringan dan penyaluran suspensi pati ke dalam bak pengendapan pati), dan pengeluaran ampas dari dalam tabung. Durasi waktuuntuk ekatraksi sesuai perlakuan yaitu 10, 15, 20 dan 25 menit sedangkanwaktu untuk pengeluaran ampas dari dalam tabung ekstraksi berkisar antara 15- 20 menit. Pada durasi waktu 3 menit awal dari proses ekstraksi, pengadukan dan peremasan berlangsung tanpa mengalirkan suspensi pati ke bak pengendapan. Pada periode ini juga tidak ditambahkan air ke dalam tabung ekstraksi. Setelah 3 menit, kran pada ujung pipa penyalur dibuka dan suspensi pati mengalir ke dalam bak pengendapan pati. Selama pengaliran suspensi pati dari dalam tabung ekstraksi ke bak pengendapan, penting untuk memperhatikan bahwa jumlah air yang dialirkan ke dalam tabung sama dengan aliran keluar agar proses berlangsung lancar. Jumlah aliran dari dalam tabung dikontrol dengan mengontrol besar kecilnya bukaan katup pada stop kran. Semakin besar debit air yang digunakan semakin efektif proses pemisahan pati dari ampas. Jika debit air yang digunakan terlalu sedikit, proses pemisahan pati tidak efektif dan banyak pati yang terbuang bersama ampas karena tidak terekstrak, sebaliknya jika terlalu banyak air yang digunakan maka biaya operasional lebih mahal.

Proses ekstraksi diakhiri sesuai masingmasing perlakuan durasi waktu dengan menghentikan (turn off) motor penggerak. Setelah itu dilakukan pengeluaran ampas dari dalam tabung untuk kemudian dilanjutkan dengan batch/proses ekstraksi berikutnya.

\section{Rendemen pati basah}

Pati dalam bak pengendapan dibiarkan selama 4 jam untuk kemudian air supernatant (supernatant water) yang berada pada lapisan bagian atas endapan pati dibuang. Pati kemudian dikumpulkan dan ditimbang massanya untuk perhitungan rendemen pati. Pada Gambar 4 ditampilkan rendemen pati pada berbagai perlakuan durasi waktu ekstraksi.

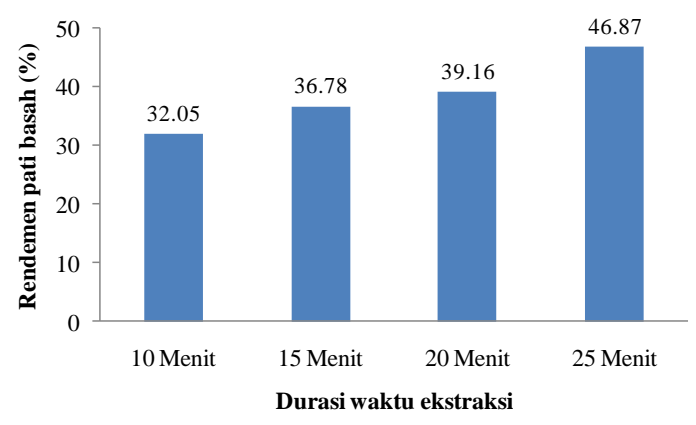

Gambar 4. Rendemen pati basah rata-rata pada berbagai durasi waktu ekstraksi

$\begin{array}{lrr}\text { Gambar } & 4 & \text { memperlihatkan bahwa } \\ \text { rendemen pati meningkat } & \text { dengan }\end{array}$ meningkatnya durasi waktu ekstraksi. Hal ini disebabkan karena semakin lama proses ekstraksi berlangsung, semakin banyak jumlah pati yang terekstrak.Hasil ini konsisten dengan hasil penelitian terdahulu dengan menggunakan lubang saringan yang lebih besar (Darma et al., 2010; 2017 dan Solissa, 2019). Beberapa faktor yang mempengaruhi jumlah pati yang dapat terekstrak antara lain efektivitas pemisahan pati dari ampas, durasi waktu proses ekstraksi, debit aliran air yang digunakan dan tingkat kehalusan hancuran empulur sagu.

Berdasarkan Gambar 4 juga menunjukkan bahwa rendemen pati tertinggi (46.87\%) diperoleh pada perlakuan durasi waktu 25 menit dan terendah $(32,05 \%)$ dihasilkan pada perlakuan waktu waktu ekstraksi 10 menit. Hasil ini sejalan dengan hasil penelitian Darma et al., (2014; 2017) yang menghasilkan rendemen pati berturut turut $\quad 35.9 \%$ dan $40,5 \%$. Hasil ini juga konsisten dengan hasil penelitian Solissa (2019) dan Darma et al., (2020) yang memperoleh rendemen pati berturut-turut $31,60-41,25 \%$ dan 33,11 - 46,67 \% (rata-rata $38,26 \%)$.

Rendemen pati disamping dipengaruhi oleh teknik pengolahan yang digunakan juga 
dipengaruhi oleh jenis sagu yang diolah. Menurut Cecil (1992), semakin halus hancuran empulur hasil parutan (repos) maka semakin banyak pati yang terbebas dan dapat terekstrak. Lebih lanjut dikemukakan bahwa saringan dengan lubang yang lebih besar memiliki kapasitas yang lebih besar, namun tidak hanya pati yang melewatinya namun juga material lainnya. Sebaliknya, saringan dengan lubang yang kecil memiliki kapasitas lebih kecil tapi dengan hasil pati yang lebih baik. Hal ini berarti bahwa penggunaan saringan dengan lubang yang lebih kecil memerlukan waktu yang lebih lama untuk memisahkan semua pati terbebas (freed starch) dari ampas. Darma (2010), melaporkan bahwa kandungan pati sagu di beberapa lokasi di Papua dan Papua Barat berkisar antara $12.43 \%-39.89 \%$ (ratarata $26.85 \%$ ).

\section{Hasilpati basah (wet starch yield)}

Hasil pati basah pada berbagai perlakuan durasi waktu ekstraksi disajikan pada Gambar 5.

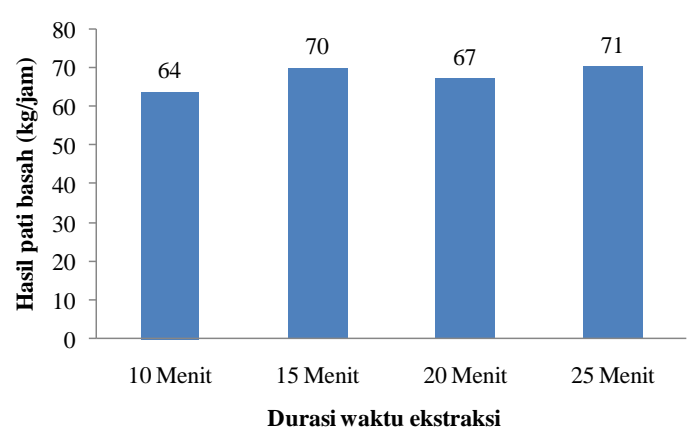

Gambar 5. Hasil pati basah rata-rata pada berbagai durasi waktu ekstraksi

Berdasarkan Gambar 5 terlihat bahwa ada kecenderungan terjadi peningkatan hasil pati dengan meningkatnya durasi waktu ekstraksi. Hal ini disebabkan karena karena rendemen pati semakin tinggi dengan meningkatnya durasi waktu ekstraksi (Gambar 4). Sebagaimana disebutkan pada persamaan (3), hasil pati berbanding lurus dengan rendemen pati $(R P)$ dan kapasitas ekstraksi $(K E)$. Walaupun kapasitas ekstraksi menurun dengan meningkatnya durasi waktu (Gambar 3), namun oleh karena gradient penurunannya lebih kecil dibandingkan dengan gradient peningkatan rendemen pati maka konsekuensinya hasil pati cenderung berbanding lurus dengan durasi waktu ekstraksi. Salah satu factor yang mempengaruhi kapasitas ekstraksi adalah ukuran lubang saringan (screen/strainer apertures). Saringan dengan lubang yang besar memiliki kapasitas ekstraksi besar namun tidak hanya pati yang melewati tapi juga material lainnya. Sebaliknya, saringan dengan lubang yang kecil memiliki kapasitas rendah, namun dengan hasil pati yang lebih murni (Cecil, 1992). Hasil penelitian ini kontradiksi dengan hasil penelitian Darma et al., (2017) dan Solissa (2019) yang menghasilkan pati basah berbanding terbalik dengan periode waktu ekstraksi.

Hasil pati basah tertinggi $(71 \mathrm{~kg} / \mathrm{jam})$ diperoleh pada perlakuan durasi waktu ekstraksi 25 menit dan terendah $(67 \mathrm{~kg} / \mathrm{jam})$ diperoleh pada periode waktu ekstraksi 10 menit. Hasil penelitian ini konsisten dengan penelitian sebelumnya (Solissa, 2019), dan Darma et al., (2014) yang menghasilkan pati basah berturut-turut $66,41-79,99 \mathrm{~kg} / \mathrm{jam}$ dan $79 \mathrm{~kg} / \mathrm{jam}$, namun lebih rendah dari hasil penelitian Darma et al., (2017 dan 2020) yang memperoleh hasil pati berturut-turut $72-100$ $\mathrm{kg} / \mathrm{jam}$ dan $93 \mathrm{~kg} / \mathrm{jam}$. Perlu ditambahkan bahwa kelebihan mesin ekstraksi dengan menggunakan saringan 100 mesh dibandingkan dengan prototype terdahulu adalah penyaringan dilakukan hanya 1 tahap, tidak ada saringan tahap-2 yang berarti peningkatan efisiensi mesin. Pada prototype terdahulu, penyaringan tahap-2 dilakukan segera setelah suspensi pati keluar dari tabung ekstraksi (sebelum dialirkan ke bak pengendapan). Saringan tahap-2 ini dilakukan secara manual sehingga butuh tambahan tenaga kerja.

\section{Kehilangan pati pada ampas (losses)}

Dalam suatu proses ekstraksi pati, tidak semua pati yang telah terbebas (freed starch) dapat terekstrak. Sebagian tidak terekstrak dan ikut bersama ampas. Semakin tinggi pati pada ampas berarti kehilangan pati (starch losses) makin besar. Persentase pati terikut ke ampas sagu pada berbagai durasi waktu ekstraksi ditampilkan pada Gambar 6.

Gambar 6 memperlihatkan bahwa semakin tinggidurasi waktu ekstraksi maka persentase pati pati pada ampas semakin rendah. Hal ini disebabkan karena peningkatan durasi waktu proses ekstraksi, semakin banyak jumlah pati yang terekstrak (Gambar 4) sehingga pati yang tertinggal pada ampas semakin sedikit. 


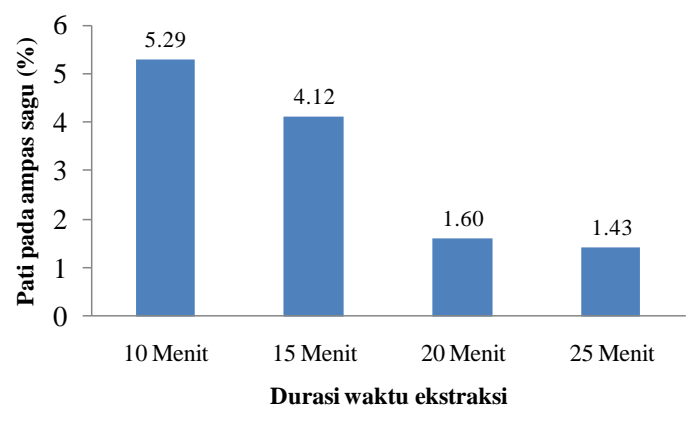

Gambar 6. Persentase pati terikut ke ampas sagu pada berbagai durasi waktu ekstraksi

Persentase pati ampas dari suatu proses ekstraksi berkorelasi negatif dengan rendemen pati. Jika persentase pati pada ampas $0 \%$ berarti semua pati terbebas (freed starch) berhasil diekstrak. Hasill ini sejalan dengan hasil penelitian terdahulu dengan menggunakan lubang saringan yang lebih besar (Darma et al, 2010; 2017; 2020 dan Solissa, 2019).Perlu ditambahkan disini bahwa persentase pati pada ampas yang diukur pada penelitian ini hanyalah pati yang telah berada dalam keadaan terbebas (freed starch) akibat telah hancurnya dinding sel jaringan empulur saat proses pemarutan. Sedangkan pati yang masih dalam keadaan tidak terbebas (unfreed starch) tetap terperangkap secara permanent dalam sel-sel parenchyma dan terbuang bersama ampas sagu.Jumlah pati padaampas tergantung derajat kehalusan ela dan efektivitas mesin ekstraksi dalam pemisahan pati dari ampas.

Persentase pati yang terikut ke ampas dihasilkan pada penelitian ini sebagaimana terlihat pada Gambar 6 antara 1,43\% - 5,29\%. Hasil ini lebih tinggi dari hasil penelitian terdahulu (Solissa., 2019) dan Darma et al., (2020) yang menghasilkan pati pada ampas berturut-turut antara $0,97-1,57 \%$ dan $0,47 \%$ - 2,22 \%, namun lebih rendah dari hasil penelitian Darma et al. (2017) yang memperoleh pati pada ampas ntara 2,4-5,6\%. Hasil penelitian Reniana et al., (2019) menghasilkan persentase pati pada ampas antara $2,34 \% \quad-5,67 \%$. Semakin tinggi persentase pati pada ampas menunjukkan bahwa semakin kurang efektifnya proses ekstraksi berlangsung dan sebaliknya. Dengan kata lain, semakin tinggi pati pada ampas maka kerugian atau kehilangan pati akibat terikut pada ampas semakin besar.

\section{KESIMPULAN}

Mesin ekstraksi pati sagu tipe stirrer rotary blade dengan menggunakan saringan 100 mesh berfungsi baik.Hasil pengujian pada berbagai durasi waktu ekstraksi menunjukkan bahwa semakin tinggidurasi waktu ekstraksi, semakin tinggi rendemen pati dan hasil pati, namun kapasitas ekstraksi, dan persentase pati pada ampas semakin rendah. Berdasarkan parameter hasil pati tertinggi dan persentase kehilangan pati pada ampas terendah makakinerja tertinggi diperoleh pada perlakuan durasi waktu ekstraksi 25 menit. Kinerja mesin pada perlakuan tersebut adalah (1) rendemen pati $46,87 \%$, (2) hasil pati 71 $\mathrm{kg} / \mathrm{jam},(3) \mathrm{kapasitas}$ ekstraksi $150 \mathrm{~kg}$ ela/jam, dan (4) kehilangan pati pada ampas 1,43\%.

\section{UCAPAN TERIMA KASIH}

Penelitian ini merupakan sebagian dari skim penelitian unggulan startegis nasional (PUSN) tahun ke-2. Penulis menyampaikan apresiasi dan terima kasih kepada Kementerian Riset, Teknologi dan Pendidikan Tinggi c.q. Direktorat Penelitian dan Pengabdian Kepada Masyarakat atas dukungan dana untuk penelitian ini.

\section{DAFTAR PUSTAKA}

Bintoro, M. H., Nurulhaq, M. I.. Pratama, A. J, Ahmad, F. and Ayulia, L., (2018), Growing Area of Sago Palm and Its Environment, in Ehara, H., Toyoda, Y. and Johnson, D.V. (Eds.). SAGO PALM: Multiple Contribution to Food Security and Sustainable Livelyhoods, Springer. Singapore, pp. 17-30.

Cecil, J.E, (1992), Small-, medium-and largescale starch processing, FAO Agricultural Services Bulletin 98, Rome.

Darma, Istalaksana, P. dan Gani, A. (2010), Prototype Alat Pengekstrak Pati Sagu Tipe Mixer Rotary Blade Bertenaga Motor Bakar, Jurnal Agritech, 30 (4), pp. 204-211.

Darma, (2010), Kandungan Pati dan Potensi Produksi Sagu Alam (Metroxylon sagu Rottb) di Papua. Jurnal Agrotek, 2(2), pp. 7-14.

Darma, (2011), Traditional processing of sago in Papua Province, Proceeding of the $10^{\text {th }}$ international sago symposium: sago 
for food security, bio-energy, and industry from research to market, Bogor, Indonesia, 29-31 October 2011, pp. $115-116$.

Darma, Wang, X. and Kito, K., (2014), Development of Sago Starch Extractor with Stirrer Rotary Blade for Improving Extraction Performance, International Journal of Engineering and Technology (IJET), 6(5), pp 2472-2481.

Darma dan Santoso, B., (2017), Variant-3 Mesin Ekstraksi Pati Sagu Tipe Stirrer Rotary Blade Bertenaga Motor Bakar Bensin, Prosiding Seminar Nasional: Mewujudkan Kedaulatan Pangan Melalui Penerapan Inovasi Teknologi Pertanian Spesifik Lokasi pada Kawasan Pertanian,Sorong, Papua Barat, 9 November, 2017, pp. 440-451.

Darma, (2018), Improvement of Sago Processing Machiney, in Ehara, H., Toyoda, Y. and Johnson, D.V. (Eds.). SAGO PALM: Multiple Contribution to Food Security and Sustainable Livelyhoods, Springer. Singapore, pp. 231-246.

Darma, Santoso, B., Reniana dan Arbianto, M.A., (2020), Kinerja Teknologi Mesin Pengolahan Sagu Skala Kecil di Kabupaten Supiori, Provinsi Papua, Jurnal Pengkajian dan Pengembangan Teknologi Pertanian, 23(2), pp. 163176.

Darma, Santoso, B. and Reniana, (2020), Development and Performance Test of Vertical Stirrer Rotary Blade Type of Sago Starch Extraction Machine, International Journal of Engineering and Technology (IJET-IJENS), 20(3), pp.110.

Dewi R. K, Bintoro M.H. dan Sudradjat. (2016), Karakter Morfologi dan Potensi Produksi beberapa Aksesi Sagu
(Metroxylon spp.) di Kabupaten Sorong Selatan, Jurnal Agron Indonesia, 44(1), pp. 91-97.

Djoprie, M.H.B, Herodian, S. dan Ngadiono, (2014), Sagu untuk Kesejahteraan Masyarakat Papua: Suatu Kajian dalam Upaya Pengembangan Sagu Sebagai Komoditas Unggulan di Provinsi Papua dan Papua Barat, Laporan Penelitian Unit Percepatan Pembangunan Papua dan Papua Barat, Jakarta.

Haryanto B, Mubekti dan Putranto, A. T., (2015), Potensi dan Pemanfaatan Pati Sagu dalam Mendukung Ketahanan Pangan di Kabupaten Sorong Selatan Papua Barat,Jurnal PANGAN, 24(2), pp. 97-106.

Jong, F. S. and C.J. Hoo, (2011), Growth and Yields of Natural Sago Forests for commercial operations, Proceeding of the $10^{\text {th }}$ international sago symposium: sago for food security, bio-energy, and industry from research to market, Bogor, Indonesia, 29-31 October 2011, pp.43-45.

Reniana, Darma dan Kurniawan, A., (2019), Kajian Proses Pemarutan Empulur Sagu Menggunakan Alat Pemarut Sagu Bertenaga Manual dan Motor Bakar, Jurnal Agritechnology, 2(2), pp.71-77.

Solissa A. T., (2019), Pengembangan Prototipe dan Uji Kinerja Mesin Ekstraksi Pati Sagu Tipe Vertikal Stirrer Rotary Blade Bertenaga Motor Bakar Bensin, skripsi, Universitas Papua, Manokwari.

Unit Percepatan Pembangunan Provinsi Papua dan Provinsi Papua Barat (UP4B), (2014), Master Plan Pengembangan Sagu Sebagai Komoditas Unggulan Provinsi Papua dan Provinsi Papua Barat. Laporan Kajian. UP4B. Jakarta. 